\title{
Assessment of serum vitamin d level in third trimester of multiparous women of sargodha region with relation to sun exposure and age group.
}

1. MBBS, DCP, M. Phill (Histo) Professor Pathology

Sargodha Medical College, Sargodha.

2. M.Phill (Human Pathology) Lecturer Islamia University of Bahawalpur.

3. MBBS, Ph.D

Assistant Professor Pathology RAK College of Medicine

RAK Medical and Health Science University,

Ras-al-Khaimah, UAE.

Correspondence Address: Dr. Abdul Haseeb Khan Department of Pathology

Sargodha Medical College, Sargodha. drabdulhksmc@ymail.com

Article received on: 02/02/2019

Accepted for publication: $11 / 07 / 2020$

\begin{abstract}
Abdul Haseeb Khan', Farzana Islam², Abdul Rehman ${ }^{3}$
ABSTRACT... Objectives: To assess serum vitamin D level in third trimester multiparous pregnant females and correlate them with different parameters (sun exposure and age). Study Design: Cross Sectional study. Setting: Department of Pathology, SMC, UOS, Sargodha. Period: April $17^{\text {th }}$ to September $17^{\text {th }}, 2017$. Material \& Methods: A total of fifty multiparous pregnant women in $3^{\text {rd }}$ trimester were included in this study. On the basis of their 25 hydroxy vitamin $\mathrm{D}(25 \mathrm{OHD})$ levels, pregnant women were categorized into 2 groups: normal (>30ng/ $\mathrm{ml}$ ) and deficient $(<20 \mathrm{ng} / \mathrm{ml})$. Vitamin $\mathrm{D}$ level was measured by CLIA (chemilumuniscence immunoassay analyzer). Data related to sun exposure and age groups was recorded on self structured questionnaire. Results: We found that 47 multiparous women (94\%) were vitamin D deficient and $3(6 \%)$ had normal vitamin D levels. Based on associated findings, results showed significance between vitamin $D$ and day time of sun exposure $(p=0.02)$, vitamin $D$ and duration of sun exposure $(p=0.01)$. A significant difference between vitamin $D$ and different age groups $(p=0.03$ ) was also observed in multiparous pregnant females. Conclusion: My study suggested that multiparous pregnant women are more susceptible to vitamin $D$ deficiency. $A$ significant association exists between vitamin $\mathrm{D}$ and day time of sun exposure, duration of sun exposure and age groups among multiparous pregnant women.
\end{abstract}

Key words: $\quad$ Multiparous, Third Trimester, Vitamin D.

Article Citation: Khan AH, Islam F, Rehman A. Assessment of serum vitamin D level in third trimester of multiparous women of Sargodha region with relation to sun exposure and age group. Professional Med J 2020; 27(11):2483-2487. https://doi.org/10.29309/TPMJ/2020.27.11.3208

\section{INTRODUCTION}

VIT D is known as a "sunshine" vitamin which is essential for growth and development of the body. ${ }^{1}$ There are two sources for human beings to obtain vitamin $\mathrm{D}$, one is endogenous source and the other is exogenous source. ${ }^{2}$ The endogenous source of vitamin $D$ is sunlight exposure and the lack of sunlight is a major cause of vitamin $D$ deficiency (VDD). ${ }^{3}$ Exogenous sources of vitamin $D$ include foods naturally enriched vitamin $D$ such as oily fish and fish liver oil. ${ }^{4}$ Its minor quantities are available in egg yolks and meat. ${ }^{5}$ It is also available in sun exposed yeast, mushrooms and vitamin $\mathrm{D}$ fortified foods. ${ }^{6}$

Normal VIT D level falls in between $30-100 \mathrm{ng} /$ $\mathrm{ml} 30 \mathrm{ng} / \mathrm{ml}$ of $25 \mathrm{OHD}$ is normal serum level. VIT $D$ insufficiency level falls in between $20-30 \mathrm{ng} / \mathrm{ml}$ while less than $20 \mathrm{ng} / \mathrm{ml}$ is considered as VDD. ${ }^{7}$ VDD causes hyperparathyroidism, rickets in children and osteomalacia in adults. ${ }^{8}$ Rickets and osteomalcia are two disorders characterized by defective bone and cartilage mineralization. ${ }^{9}$

VDD is supposed to be a major public health crisis in many areas of the world ${ }^{10}$ and in Pakistan VDD is more prevalent. ${ }^{11}$ In majority of communities, VDD or VDI is most common in pregnancy. ${ }^{12}$ In Pakistan, a number of studies have shown vitamin $D$ deficiency in pregnant women. ${ }^{13}$

An important risk factor for VDD is maternal parity due to depletion of vitamin $D$ reserves in the body particularly when there is lack of vitamin $D$ fortified foods, supplements or imbalanced diet during pregnancy. ${ }^{14}$ Most common etiological factor involved in VDD is insufficient sun exposure because those individuals who spend their most of time in sunlight have normal level of VIT D status. ${ }^{15}$ The synthesis of VIT D is also decreased 
due to aging and decreased functional capacity of skin. ${ }^{16}$ Keeping all the above facts in view, present study is carried out to assess serum vitamin D level in $3^{\text {rd }}$ trimester multiparous pregnant females and to find out an association with sun exposure and age groups.

\section{MATERIAL \& METHODS}

A cross sectional study was conducted on third trimester pregnant women reporting in government and private health sectors in Sargodha district, Punjab, Pakistan. This research work was completed in six months from $17^{\text {th }}$ April to September $17^{\text {th, }}$ 2017. Fifty 3rd trimester pregnant multiparous women were included in this study. No probability purposive sampling technique had been used. Females included in this study having age of 20-35years, $3^{\text {rd }}$ trimester, multiparous and no medication history known to affect endocrinal parameters were included in my research work. Females having less than 20 and more than 35 years of age, $1^{\text {st }}$ and $2^{\text {nd }}$ trimester and having history of DM, CVD, chronic renal failure, chronic hepatic disorders, autoimmune diseases and chronic infections were excluded.

I took consent on Performa I from selected and agreed subjects while history and questions related to associate risk factors had been noted down on Performa II. I collected $5 \mathrm{ml}$ venous blood into blood collection tube, centrifuged and separated serum part. Serum vitamin D levels were estimated by fully automated chemiluminiscence immunoassay analyzer (CLIA) Maglumi 1000. Data was analyzed statistically by SPSS Version 20. Frequencies of Various groups of subjects according to vitamin $D$ status were determined. Correlations of vitamin D to different age groups, day time of sun exposure, duration of sun exposure were carried out by Chi square test.

\section{RESULTS}

During the study period, 50 third trimester multiparous pregnant women had been involved. 47 (94\%) were vitamin D deficient and $3(6 \%)$ had normal serum vitamin D levels.

\begin{tabular}{|c|l|c|c|}
\hline \multicolumn{2}{|c|}{ Patient's Distribution } & Frequency & Percent \\
\hline \multirow{4}{*}{ Valid } & Vitamin D deficient & 47 & 94.0 \\
\cline { 2 - 4 } & Normal vitamin D level & 3 & 6.0 \\
\cline { 2 - 4 } & Total & 50 & 100.0 \\
\hline
\end{tabular}

Table-I. Vitamin D status in $3^{\text {rd }}$ trimester multiparous pregnant females.

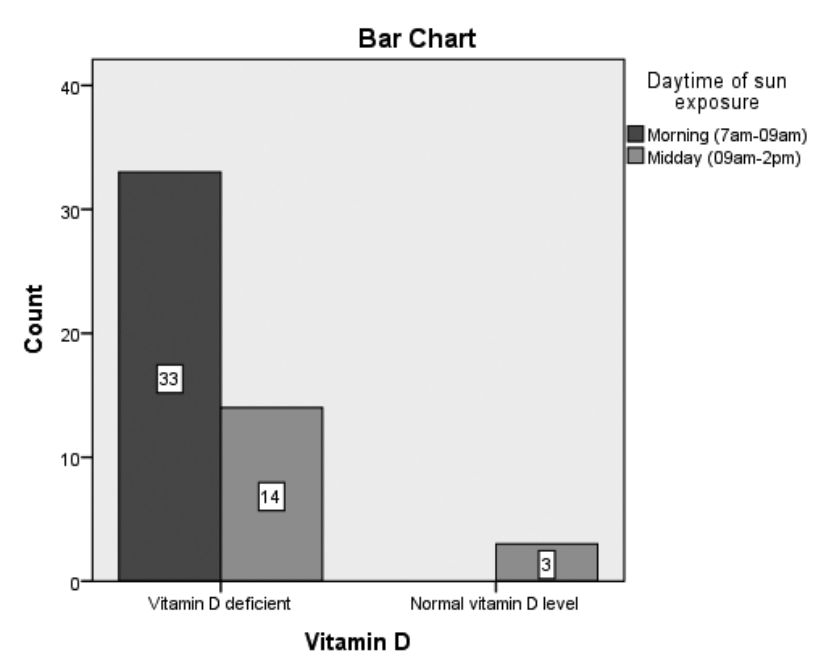

Figure-1. Vitamin D and daytime of sun exposure.

In this study 33 females got sun exposure in morning time (7am-9 am) and all were vitamin D deficient. 17 females were those who took sunlight in midday (9 am-2pm) out of them $3(17 \%)$ had normal vitamin D levels. There was statistically significant association between vitamin $D$ levels and daytime of sun exposure $(P=0.02)$.

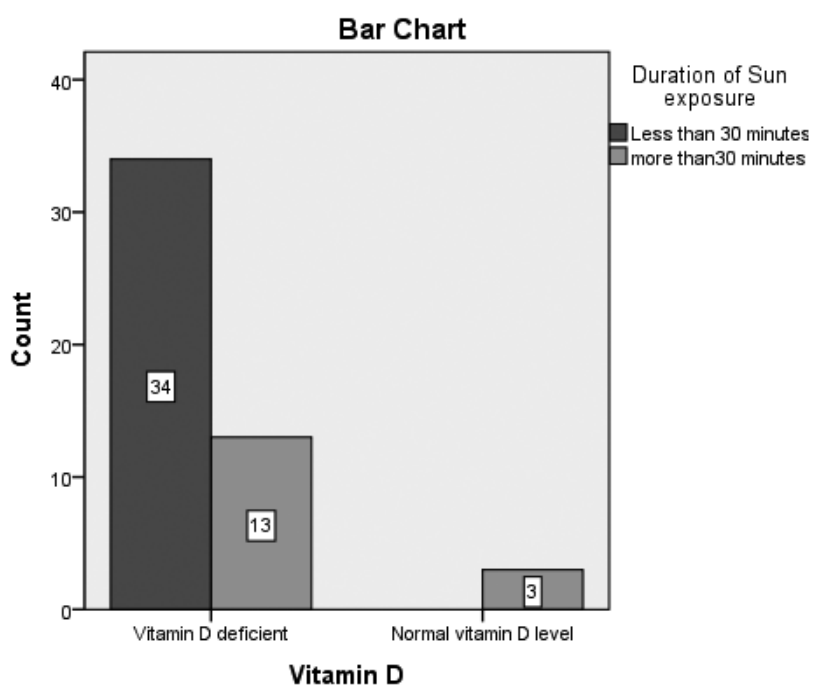

Figure-2. Vitamin D and duration of sun exposure. 
This figure shows thirty four women's duration of sun exposure was less than 30 minutes and all were vitamin D deficient. Sixteen women's duration of sun exposure was more than 30 minutes and among them 3 women had normal serum vitamin D levels. A strong correlation was found between serum Vitamin $D$ and duration of sun exposure $(\mathrm{P}=0.01)$.

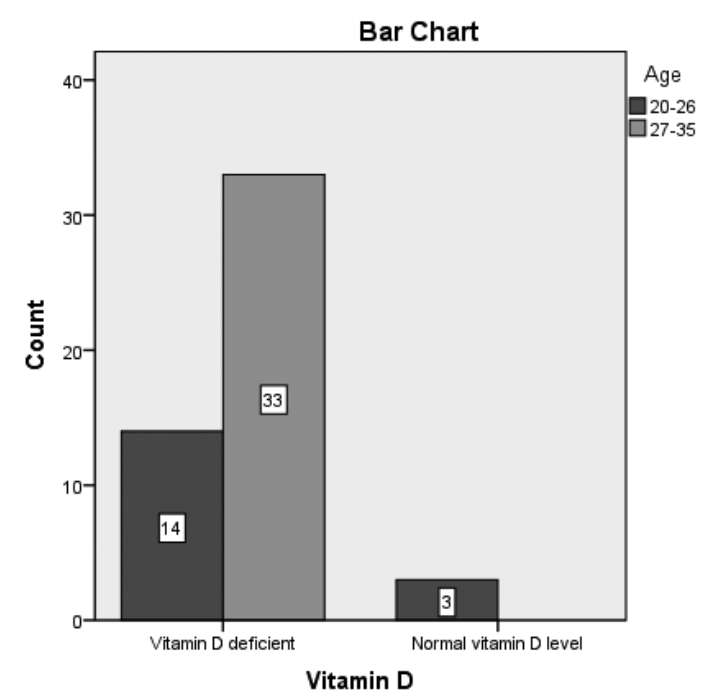

Figure-3. Serum vitamin D levels and age groups.

In present study there were two age groups: group A (20-26) and group B (27-35). 17 women reported in group A and among them 3 women's vitamin D status was normal. 33 females presented in group $B$ and all were vitamin $D$ deficient. There was statistically significant association between vitamin $D$ levels and age groups $(P=0.03)$.

\section{DISCUSSION}

The present study was carried out to assess serum vitamin $\mathrm{D}$ level in third trimester of 50 multiparous women of Sargodha district with relation to age groups and sun exposure. Our results showed that out of 50 multiparous females, 47 (96\%) were VDD and $3(6 \%)$ had normal VIT D levels. This is in accordance with other studies which reported VDD in $3^{\text {rd }}$ trimester of pregnant females. ${ }^{13} \mathrm{~A}$ study from Pakistan involved 50 pregnant females at term to assess VIT D levels. They found 23(46\%) were VDD, 16(32\%) as VDI and 11 (22\%) had normal vitamin $D$ levels. ${ }^{17}$ Another study from Pakistan reported low vitamin D levels in $87.7 \%$ of pregnant females of last trimester and normal serum vitamin D levels in $12.03 \%$ females. ${ }^{18}$ Gharaibeh and Stoecker, (2009) suggested from their study that serum vitamin $\mathrm{D}$ deficiency is more prevalent in grand multiparous as compared to primiparous females. Dratva et al., 2006 have shown that multiparous females should take supplements regularly during pregnancy and lactation because multiparity has been strongly linked to vitamin D deficiency. ${ }^{19}$

As it is clearly evident from previous researches, vitamin $D$ is endogenously synthesized in human skin and aging reduce the capability of human skin to produce vitamin D. ${ }^{20}$ In present study age was divided into age groups; 20-26 and $27-35$ years respectively. In $1^{\text {st }}$ age group $82 \%$ females were vitamin D deficient and18\% females had normal vitamin $D$ levels. Meanwhile in $2^{\text {nd }}$ age group all females were vitamin $\mathrm{D}$ deficient. There was a strong correlation between VDD and age groups $(p=0.03)$.

In another study, researchers estimated vitamin D capacity in young and older subjects. After comparative assessment of vitamin $D$ levels in both groups (young and old) they concluded that human skin capability is decreased more than two folds with aging. ${ }^{21}$

Results indicate that vitamin $D$ is necessary for the improvement and maintenance of a healthy skeleton in humans, because it is proved that after age of 20 years skin thickness decreased gradually with age and vitamin D synthesis is also decreased. Therefore, fortification of vitamin $D$ with food is necessary to avoid complications occurring due to vitamin $D$ deficiency e.g. osteoporotic bone fractures, osteomalacia and physiological stress during pregnancy.

Vitamin D is endogenously synthesized in sunlight exposure and deficiency of sunlight is a major cause of vitamin D deficiency. Our results showed, vitamin $\mathrm{D}$ deficiency was more common in those pregnant females who get sunlight exposure in morning time when plentiful sunshine had not been available and whose duration of sunlight exposure was less than 30 minutes. Our results showed a strong association) of serum vitamin 
$D$ levels with daytime of sunlight exposure $(p=$ $<.02)$ and duration of sun exposure $(p=0.01)$.

Binkley et al., (2007) had done a research work and involved 93 participants (63 males and 30 males). They observed that serum vitamin $D$ level of sun exposed people was $60 \mathrm{ng} / \mathrm{ml} .^{22}$

This was the first study in district Sargodha, Punjab, Pakistan in which vitamin D status was estimated in $3^{\text {rd }}$ trimester of multiparous women in different age groups with relation to sun exposure.

\section{CONCLUSION}

Data in current study indicate that VIT D level decreases with parity status. A significant association exists between vitamin D status and age groups. Day time and duration of sun exposure were also found associated with VDD.

Copyright@ 11 July, 2020.

\section{REFERENCES}

1. Ahasan HN, Das A. Vitamin D deficiency in south $\begin{array}{ll}\text { Asian population JEMC. 2013; } & 3(2): 63-66 .\end{array}$

2. Alpert PT, Shaikh $U$. The effects of vitamin D deficiency and insufficiency on the endocrine and paracrine systems. Biol Res Nurs. 2009; 9(2):117-129.

3. Holick MF, Chen TC, Lu Z, Sauter E. Vitamin D and skin physiology: A Delightful story. J Bone Miner Res. 2007; 22(2); 28-33.

4. Raiten DJ, Picciano MF. Vitamin D and health in the 21st century: Bone and beyond executive summary. Am J Clin Nutr. 2004; 80(6):1673-1677.

5. Jasinghe VJ, Perera CO, Barlow PJ. Bioavailability of vitamin D2 from irradiated mushrooms: An in vivo study. Br J Nutr. 2005; 93(6):951-955.

6. Bischoff-Ferrari H. Vitamin D: what is an adequate vitamin $D$ level and how much

supplementation is necessary. Best Pract Res Clin Rheumatol. 2009; 23(6):789 795.

7. Bordelon P, Ghetu MV, Langan RC. Recognition and management of vitamin $D$ deficiency. Am Fam Physician. 2009; 80(8):841-6.

8. Barrett $H$, McElduff $A$. Vitamin $D$ and pregnancy: An old problem revisited. Best Pract Res Clin Endocrinol Metab. 2010; 24(4):527-39.
9. Nasir AM, Sharifah DA, Abdullah NA, Hessah M N, Amir MI. Thyroid disorders associated with Type 1 diabetes mellitus in children and adolescents from Central Province Saudi Arabia. Int J Curr Res Biosci Plant Biol. 2015; 2(1):45 49.

10. Holick MF. High prevalence of vitamin D inadequacy and implications for health. Mayo Clin Proc. 2006; $81(3): 353-373$.

11. Hossain N, Khanani R, Hussain-kanani F, Shah T, Arif S, Pal L. High prevalence of vitamin D deficiency in Pakistani mothers and their new borns. Int J Gynecol and Obstet. 2011; 112(3):229-233.

12. Dror DK, Allen LH. Vitamin D inadequacy in pregnancy: Biology, outcomes, and interventions. Nutr Rev. 2010; 68(8):465-77.

13. Zuberi LM, Habib A, Haque N, Jabbar A. Vitamin D Deficiency in ambulatory patients. J Pak Med Assoc. 2008; 58(9):482-484.

14. Jensen CB, Petersen SB, Granstrom C, Maslova E, Molgaard, C, Olsen SF. 2012. Sources and determinants of vitamin $D$ intake in Danish pregnant women. Nutrients. 2012; 4(4):259-272.

15. Hollis BW. Circulating 25-hydroxyvitamin D levels indicative of vitamin D sufficiency: Implications for establishing a new effective dietary intake recommendation for vitamin D. J Nutr. 2005; 135(2):317-22.

16. Lips et al. Once-weekly dose of 8400 IU vitamin D (3) compared with placebo: Effects on neuromuscular function and tolerability in older adults with vitamin D insufficiency. Am J Clin Nutr. 2010; 91(4):985-991.

17. Shabbir S, Sultana S, Saleem M, Ahmed F. Vitamin d deficiency in pregnant women and their new born. Sheikh Zayed Med. Coll. 2015;6(1):778-81.

18. Gharaibeh MA, Stoecker BJ. Assessment of serum $25(\mathrm{OH}) \mathrm{D}$ concentration in women of childbearing age and their preschool children in Northern Jordan during summer. European journal of clinical nutrition. 2009 Nov;63(11):1320-6.

19. Dratva J, Merten S, Ackermann-Liebrich U. Vitamin D supplementation in Swiss infants. Swiss medical weekly. 2006; 136(29-30):473-481.

20. Holick MF. Vitamin D deficiency in 2010: Health benefits of vitamin $D$ and sunlight: A D-bate. Nat Rev Endocrinol. 2010; 7(2):73-5.

21. MacLaughlin J, Holick MF. Aging decreases the capacity of human skin to produce vitamin D3. J Clin Invest. 1985; 76(4):1536-8. 
22. Binkley N, Novotny R, Krueger D, Kawahara T, Daida YG, Lensmeyer G, Hollis BW, Drezner MK. Low Vitamin D status despite abundant sun exposure. J Clin Endocrinol Metab. 2007; 92(6):2130-5.

\begin{tabular}{|c|c|c|c|}
\hline \multicolumn{4}{|c|}{ AUTHORSHIP AND CONTRIBUTION DECLARATION } \\
\hline Sr. \# & Author(s) Full Name & Contribution to the paper & Author(s) Signature \\
\hline 1 & $\begin{array}{l}\text { Abdul Haseeb Khan } \\
\text { Farzana Islam } \\
\text { Abdul Rehman }\end{array}$ & $\begin{array}{l}\text { Conceptualization of study } \\
\text { design, lab analysis. } \\
\text { Data collection, write up, data } \\
\text { analysis. } \\
\text { Literature search, proof reading. }\end{array}$ & \\
\hline
\end{tabular}

